\title{
MARGIN WIDTH, INTERNAL LINE ANGLE AND LABIAL EMERGENCE PROFILES OF MAXILLARY METALLOCERAMIC CROWNS
}

N.A. Yahya, C.C. Youngson. Margin width, internal line angle and labial emergence profiles of maxillary metalloceramic crowns. Annal Dent Univ Malaya 2007; 14: 7-13.

\section{ABSTRACT}

The purpose of this study were to compare the emergence profiles of crowns with their contralateral tooth, in vitro, and to determine if there is any association between the design of tooth preparations and the resultant emergence profile. 50 working models used for single crown construction were examined. Measurements of the faciolingual width of the crowns and contralateral teeth were taken using digital calipers. Internal line angles and the margin width of dies and the emergence profile of the corresponding crowns were measured from longitudinally sectioned polyvinylsiloxane indices mounted on a flat-bed scanner using image analysis software. Using Students t tests, no statistically significant differences $(p>0.05)$ were found for shoulder width (mean $0.94 \pm 0.23 \mathrm{~mm}$ ), internal line angle (mean $105.83 \pm 13.57^{\circ}$ ) or emergence profiles $\left(28.56 \pm 12.95^{\circ}\right)$ in the different (anterior, premolar or molar) preparations or crowns. The mean emergence profiles for all crowns was statistically significantly greater $(\mathrm{p}<0.001)$ than the contralateral tooth (mean $15.33 \pm 7.77^{\circ}$ ). Using linear regression, there was a weak statistical relationship between emergence profile and margin width (Emergence profile $^{\circ}=31.352-2.973 \times$ margin width $\left.(\mathrm{mm})\right)$. There was no statistical association between the internal line angle and the resultant emergence profile. In conclusion, the emergence profiles of crowns were higher than the contralateral teeth. Maxillary metalloceramic crown preparations had shoulder widths that did not conform to recommendations in standard texts but line angles were within a satisfactory range. The margin width exerts a weak effect upon the emergence profile of the crown.

Key words: emergence profile; crown preparation; shoulder width

\section{INTRODUCTION}

The interrelationship between the periodontium and restorative dentistry has been recognized since the principle of "extension for prevention" into the gingival margin by a cavity was introduced by G.V.
Original Article

\author{
N.A. Yahya ${ }^{1}$, C.C. Youngson ${ }^{2}$ \\ ${ }^{1}$ Department of Conservative Dentistry, \\ Faculty of Dentistry, University of Malaya, \\ Kuala Lumpur 50603, Malaysia \\ Email:nazlin@um.edu.my \\ ${ }^{2}$ Unit of Restorative Dentistry, \\ Department of Clinical Dental Sciences, \\ Liverpool University Dental School, \\ Pembroke Place, Liverpool, L3 5PS, \\ United Kingdom
}

Corresponding author: Dr Noor Azlin Yahya

Black in 1908 (1). Sixty years later, Löe (2) published an article on the reaction of gingival tissues to restorative procedures and emphasized that placing restorative margins below the gingival crest was a major factor in causing periodontal disease. In 1974, Ramfjord (3) stated that the purpose of restorative dentistry is to restore and maintain health and functional comfort of the natural dentition combined with producing a satisfactory aesthetic appearance. Therefore, regarding surface and functional characteristics, all dental restorations should comply with established requirements for periodontal physiology and health. Yap and Ong (4) supported this view in their review article by suggesting that in the treatment planning, during the operative and laboratory phases of prosthodontic work, a restorative dentist should pay due respect to the periodontium to ensure long-term success.

Crown margins may be located supragingivally, at the gingival crest or subgingivally. Evidence from several studies favours the placement of supragingival margins whenever possible $(3,5,6)$ as inflammatory response is universally associated with subgingival margins (7-10). However, the fit and quality of the margins of restorations, both provisional and final, are important determinants of periodontal health. Lang et al. (11) reported that overhanging margins not only accumulate more plaque compared to appropriately finished margins, but the plaque also undergoes a change in composition to that usually associated with destructive periodontitis. Restoration contour has also been considered an important parameter in the maintenance of periodontal health. Various theories have been proposed: the gingival protection theory $(12,13)$, the "food deflection theory" (14); gingival 
stimulation theory; muscle action theory (15) and the plaque retention theory (16). The latter theory, which suggests that overcontoured restorations accumulate plaque close to the gingival margin resulting in gingival inflammation, is the most widely accepted, however one recent clinical study (17) has shown that there may be other factors involved, including the material from which the crown is constructed.

\section{Emergence profile}

Emergence profile has been defined as "that portion of the axial tooth contour extending from the base of the gingival sulcus past the free margin of the gingiva into the oral environment" (18). Development of an appropriate emergence profile in a restoration benefits aesthetics, morphological accuracy, and functional interrelationships (19). This is a recognised problem when restoring the dentition with implant supported prosthesis and various techniques have been described to gain a reasonable emergence profile in the final restoration (20). Natural teeth exhibit a tooth profile that is straight and continues to the height of contour as it emerges from the gingival sulcus (18). Selection of a straight emergence profile for dental restorations facilitates the effectiveness of oral hygiene procedures in the gingival sulcus area (21) and an attempt should be made to flatten the facial and lingual contours of restorations to enable the most effective removal of plaque (22). To produce this flat or straight profile, an artificial crown requires sufficient tooth reduction in the gingival third of the preparation $(23,24)$ and some methods of prescribing the desired emergence profile is preferable (25).

Goodacre et al. (26) concluded that the selection of finish lines used with metal ceramic crowns should not be based on marginal fit but on personal preference, aesthetics, ease of formation, and type of metal ceramic crown (metal marginal collar versus collarless design) being fabricated. A flat shoulder is the labial finishing line most commonly taught in UK and USA dental schools $(27,28)$. This design is said to facilitate desirable aesthetics and can improve marginal stability during the porcelain firing cycle (29).

To allow the technician to produce a flat emergence profile, the ideal shoulder should be prepared to allow for optimum thickness to accomodate both metal and porcelain, and should therefore, be between 0.8 to $1.5 \mathrm{~mm}$ in width (30). Seymour et al (31) examined the shoulder width and angulation of margin preparations for metal ceramic crowns. They found that there were deficiencies in shoulder preparations, particularly in width $[0.752$ $\mathrm{mm}( \pm 0.174 \mathrm{~mm})]$. These inadequacies may have implications for periodontal health in a clinical situation if the technician attempts to obtain adequate cervical aesthetics. If maintaining a normal emergence profile is important, then wider shoulder margins, taking due consideration for pulpal health, allows easier fabrication of appropriately contoured crowns while improving rigidity and aesthetics (32).

The primary purpose of the current investigation was to compare the emergence profiles of crowns with their contralateral natural teeth identified on a working model. The null hypothesis is that there would be no difference between these profiles. A secondary aim was to determine if there is any association between the design of tooth preparations and the resultant emergence profile.

\section{MATERIALS AND METHODS}

Following local Ethical Committee's approval, 50 working models from a commercial dental laboratory where single unit metal ceramic crown had been prescribed were examined. Selection criteria for inclusion in the study were:

1. The prescribed metal ceramic crown was not part of a fixed or removable prosthesis.

2. The control tooth was the contralateral tooth in the same arch, and was not part of a prosthesis, and appeared to be unrestored on the facial and lingual surfaces.

3. Both the prepared and contralateral teeth appeared to be in a normal position within the arch.

4. The required landmarks on the preparation, the crown and contralateral tooth were shown in sufficient detail to enable replication with a putty index.

The working models were chosen at random without identification of the subject, their age or gender. Measurements of the maximum faciolingual tooth width of crowns and contralateral natural teeth were carried out directly on the model in the laboratory using the digital calipers (Mitutoyo Ltd., UK) by single operator. Each reading was taken three times and the means calculated. Other variables were measured indirectly from a sectioned silicone putty index. Twenty-two anterior teeth (incisors and canines), 13 premolars and 15 molars were examined.

Putty indices of the crown on the die, the natural contralateral tooth and the die itself were recorded using polyvinylsiloxane impression material, (President, Coltene/Whaledent Inc.,USA). Each putty index was sectioned once longitudinally and in a bucco-palatal direction through the midline of the crown at $1.0 \mathrm{~mm}$ in thickness. The sectioned indices were then mounted on a piece of paper at a standardized orientation, supported as necessary with a clear tape to aid stability. These were then placed on the scanning bed of a flat-bed scanner (HP Scan Jet 3400c, Hewlet Packard). Scanning was 
performed with a millimeter scale rule included for calibration. Analysis of the scanned images was carried out using QuickCAD Millenium edition software (Autodesk Ltd, Surrey, UK).

The shoulder width and internal line angles of the dies, in the plane of section, were measured using the QuickCAD software. The width of the margin was measured from point $\mathrm{A}$ to point $\mathrm{B}$, as shown in Fig. 1. For the internal line angle, two straight lines were drawn (axis $\mathrm{x}$ and $\mathrm{y}$ ). The angle between these two lines was measured (Fig. 2). The shoulder widths and internal line angles were combined for each tooth type before analysis. Where a chamfer was observed, the deepest aspect of the preparation (from the axial wall to the preparation margin) was measured.

The emergence profiles of both the crown and the contralateral tooth were measured from the respective indices using QuickCAD software. An estimation was made regarding the long axis of the tooth from the putty index. An assumption was made that the root of the tooth was in line with the coronal structure and therefore its long axis would fall through the midline coronally. A straight line was therefore drawn through the middle of the sectioned index (Fig. 3). A second straight line was drawn at the tangent of the labial/buccal surface of the tooth. The angle was measured where both lines intercepted each other. This angle represented the angle of the emergence profile at that point.

Statistical analysis of the data was carried out using SPSS version 11.0. Descriptive statistic was employed to compare emergence profile of the crown and the contralateral tooth; the margin widths and the internal line angles of preparations. Linear regression analysis was used to determine if there was any association between the design of the preparation and the resultant emergence profile.

\section{RESULTS}

Only two forms of labial margins were found on the working models, these were either butt-ended shoulder or chamfer as detailed in Table 1. No statistically significant differences $(p>0.05)$ were found for shoulder width, internal line angle or emergence profiles in the different tooth type (anterior, premolar or molar) preparations or crowns.

The measurement of the mean and standard deviations of faciolingual widths of the crown and contralateral tooth, by tooth type are shown in Table 2 and the internal line angles and margin widths are shown in Table 3.

\section{Measurement of emergence profile:}

The results of the emergence profile measurement of contralateral natural and restored tooth are shown in Table 4. The Student's t test
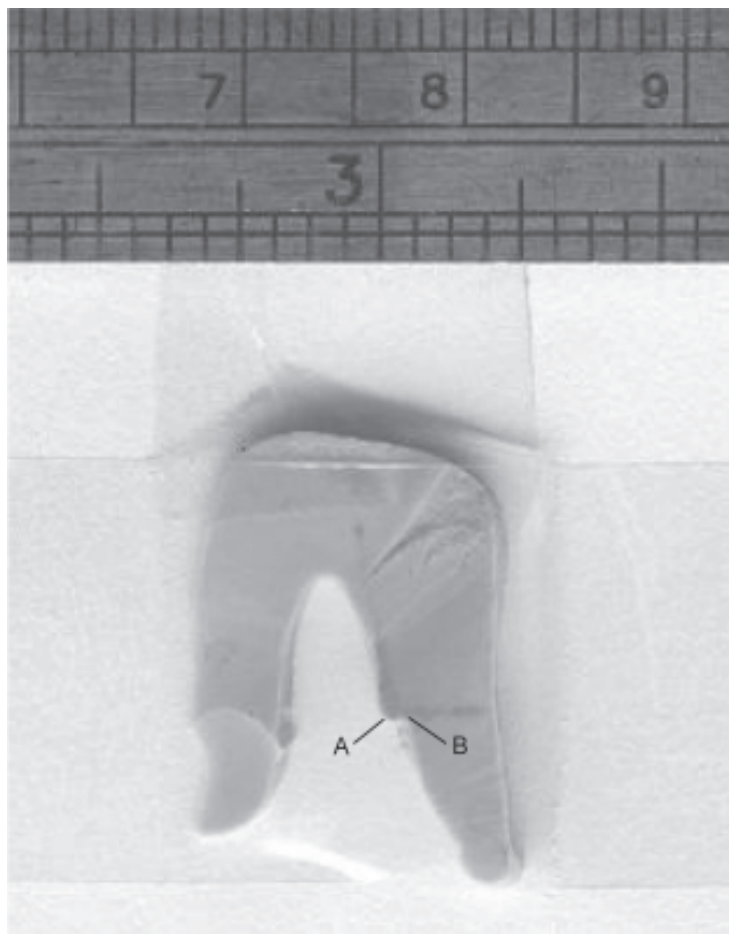

Figure 1: Measurement of marginal width from index.

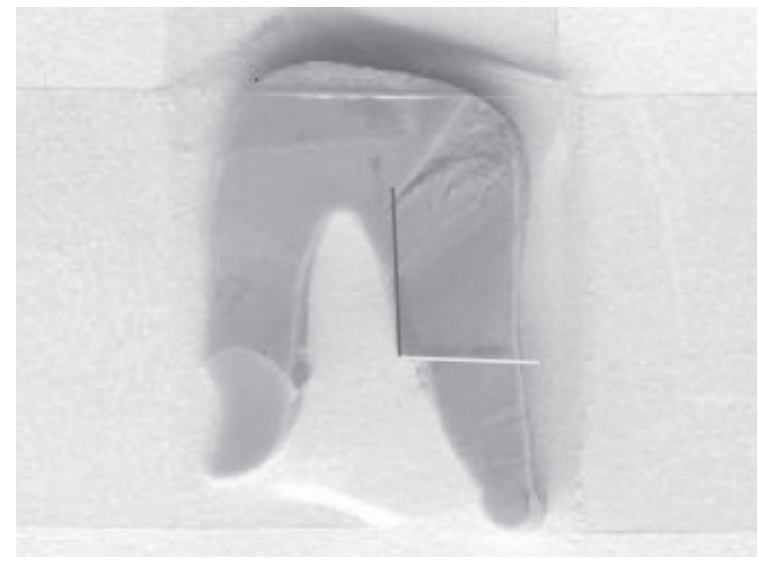

Figure 2: Measurement of internal line angle.

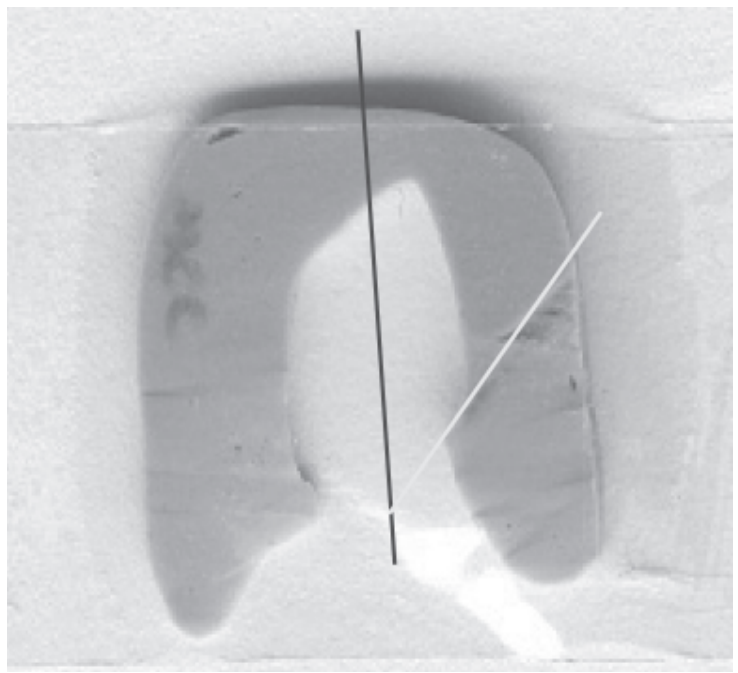

Figure 3: Measurement of emergence profile from index of a crown. 


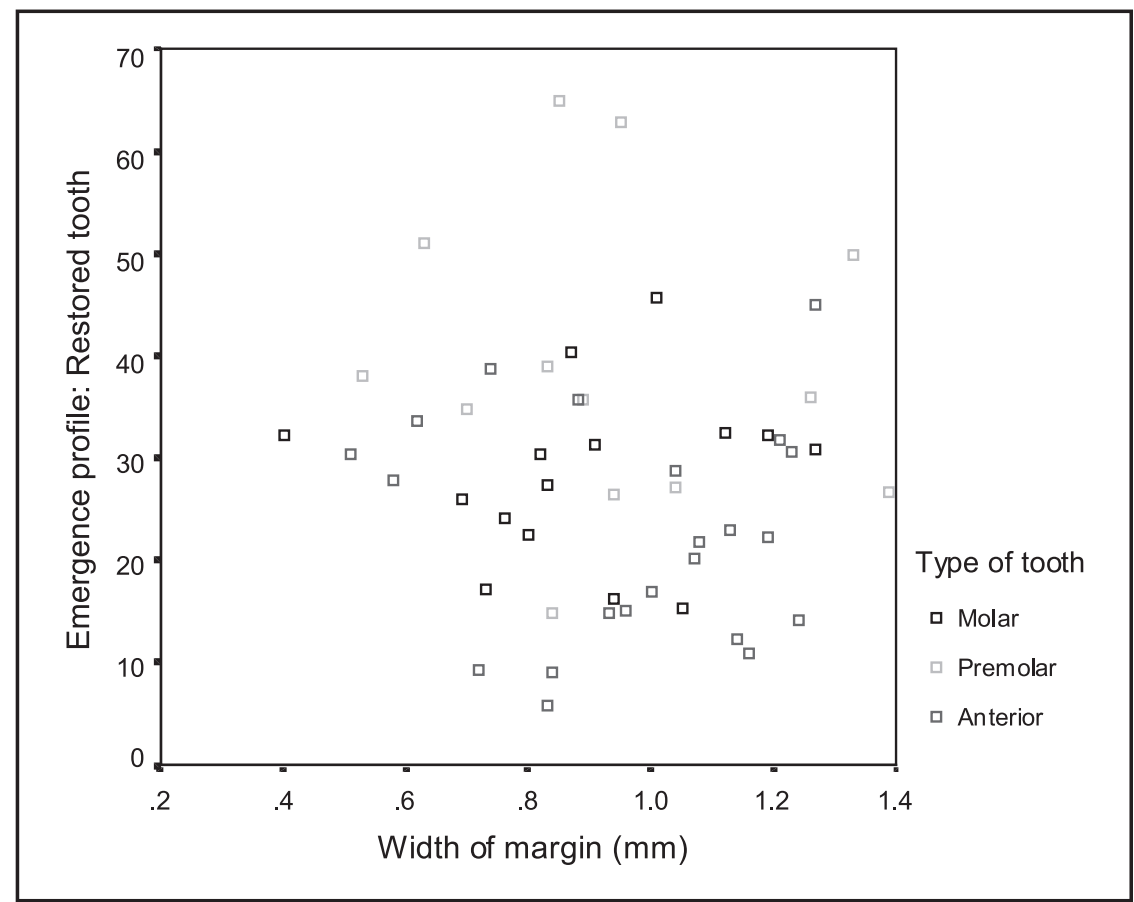

Figure 4: Scatterplot of emergence profile (restored tooth) against width of margin in different types of tooth.

Table 1. Percentage incidence of labial cervical margins

\begin{tabular}{lcc}
\hline Tooth & Shoulder $\%$ & Chamfer $\%$ \\
\hline Anterior & 82 & 18 \\
Premolar & 54 & 46 \\
Molar & 87 & 13 \\
All groups & 76 & 24 \\
\hline
\end{tabular}

Table 2. Mean maximum faciolingual width of crowns and contralateral teeth

\begin{tabular}{lccc}
\hline $\begin{array}{l}\text { Mean (SD) } \\
\text { faciolingual } \\
\text { width }(\mathrm{mm})\end{array}$ & Anterior & Premolar & Molar \\
\hline Tooth & $7.38(0.91)$ & $9.57(0.42)$ & $10.76(0.86)$ \\
Crown & $8.08(0.81)$ & $9.72(0.55)$ & $11.03(0.99)$ \\
\hline
\end{tabular}

showed that there was statistically significant difference $(\mathrm{p}<0.05)$ between the emergence profiles of the crowns and the contralateral teeth for each tooth type.

Linear regression analysis was carried out to determine if there was an association between the shoulder width, the internal line angles and the resultant emergence profile:

\section{Shoulder width:}

For the shoulder width the following values were obtained: $r^{2}$ value $0.003,95 \%$ C.I. -19.114 to 13.167 , $\mathrm{t}$-value -0.370 . The data were approximately normally distributed and so the values of the dependent variable (the emergence profile of the crown) could be predicted. The regression equation was:

Table 3. Mean internal angle and shoulder width by tooth type

\begin{tabular}{|c|c|c|c|c|}
\hline Mean (SD) & Anterior & Premolar & Molar & All groups \\
\hline Internal angle $\left({ }^{\circ}\right)$ & $103.56(12.44)$ & $111.77(14.07)$ & $104.01(14.07)$ & $105.83(13.57)$ \\
\hline Margin width $(\mathrm{mm})$ & $0.97 \quad(0.23)$ & $0.94 \quad(0.26)$ & $0.89 \quad(0.22)$ & $0.94 \quad(0.23)$ \\
\hline
\end{tabular}

Table 4. Emergence profile of crown and contralateral tooth by tooth type

\begin{tabular}{lcccc}
\hline $\begin{array}{l}\text { Mean }{ }^{\circ}(\mathrm{SD}) \\
\text { emergence profile }\end{array}$ & $\begin{array}{c}\text { Anterior } \\
\mathrm{n}=22\end{array}$ & $\begin{array}{c}\text { Premolar } \\
\mathrm{n}=13\end{array}$ & $\begin{array}{c}\text { Molar } \\
\mathrm{n}=15\end{array}$ & $\begin{array}{c}\text { All teeth } \\
\mathrm{n}=50\end{array}$ \\
\hline Crown & $22.61(10.76)$ & $38.99(14.68)$ & $28.24(8.49)$ & $28.56(12.95)$ \\
Control & $13.32(9.23)$ & $17.75(6.35)$ & $16.19(6.02)$ & $15.33(7.77)$ \\
Student's t test & $\mathrm{p}<0.0037$ & $\mathrm{p}<.0001$ & $\mathrm{p}<0.0001$ & $\mathrm{p}<0.001$ \\
\hline
\end{tabular}


Emergence profile of crown $\left(^{\circ}\right)$

$=31.352-2.973 \times$ margin width $(\mathrm{mm})$

No statistically significant association was found between the internal line angle and the emergence profile ( $r^{2}$ value 0.042 , 95\% C.I. -21.118 to 36.728 , t-value 1.454).

\section{DISCUSSION}

One-third of dentate adults in the UK have one or more crowns (33). There has been an increase in the proportion of the population who have crowns from $26 \%$ in 1988 to $34 \%$ in 1998 (33). The metal ceramic crown is believed to be the most widely used extracoronal restoration in the UK.

A number of factors should be taken into consideration, when preparing a tooth to receive a crown. The quality of crown design produced should satisfy both aspects of prosthodontics and periodontics.

Poor design of crown preparation may lead to problems not only for the dentist and technician but also for the patient. This study focused on the emergence profile of the restored tooth and investigated whether there was any association with crown design.

Croll (18) photographed several hundred extracted teeth in order to measure emergence profiles. Photographic prints reduced the three dimensional objects to dimensions for evaluation similar to that used by draughtsmen presenting complex objects in mechanical drawing. A straight edge placed on the photograph provided a gauge to evaluate relative straightness, convexity and concavity of the tooth surfaces. Anatomic observations were also recorded from intraoral photographs of natural teeth, photographs of mounted diagnostic casts in cross section, and radiographs of teeth made by using a parallel cone technique in vivo.

Seymour et al. (34) stated that the ideal internal line angle should be in the range of 90 to 110 degrees and the majority of the current samples fell within this range. In 1996, Seymour et al. (31) further examined 24 extracted human teeth, prepared to receive metal ceramic crowns. The preparations were replicated and scanned in the midfacial plane by a coordinate measuring machine with a non contact probe recording $\mathrm{x}, \mathrm{y}$, and $\mathrm{z}$ surface co-ordinates. Images constructed were superimposed and plotted where shoulder width value and internal line angles could be obtained. They found that there were deficiencies in shoulder preparations, particularly in width (mean $0.752 \mathrm{~mm}( \pm 0.174 \mathrm{~mm})$ ). This appears to be supported by our current results which used a slightly different, indirect, methodology.

Alhouri et al (35) did a study to determine whether artificial crowns were overcontoured. The methodology used are almost similar with the current investigation which used thin sections of silicone putty impressions of the buccal and lingual surfaces of full crown restorations and their natural contralateral teeth. A thin slice of the putty was obtained in the mid-tooth bucco-lingual plane and a digital image was captured and this was analysed to produce a data set $(\mathrm{x}, \mathrm{y})$ representing the curvature of the tooth surface. Using mathematical analysis, they found that most artificial crowns were either similarly or undercontoured when compared with their natural contralateral teeth. When overcontouring was present in the artificial crowns this tended to occur on the lingual aspects of anterior and posterior crowns.

In the current investigation it was clear that the crowned teeth had statistically significantly greater emergence profiles than their corresponding contralateral teeth. This may be of considerable significance to both aesthetics and long term periodontal health associated with this tooth if plaque can harbour in the bulbosity area near the gingival margin. Although beyond the remit of this study, further investigation into this possibility is required.

Other than the maximum faciolingual width of the contralateral natural and restored tooth, results regarding the tooth preparation were combined together for statistical purposes, ignoring the different type of tooth. This approach was chosen as it was considered that these parameters are defined by the restorative materials being used in a metalloceramic crown and this does not vary according to tooth type.

The most frequently encountered type of midfacial margin in this study was the shoulder. The percentage of shoulder margins overall was $76 \%$ compared to $24 \%$ chamfer margins. It has been observed (27) that a flat shoulder is the labial finishing line most commonly taught in British dental schools and this appears to be continued into practice in the UK. The relatively small sample size with chamfers prevented any association between these two types of margin and the resultant emergence profile from being observed.

As would be expected, the faciolingual widths of crowns and contralateral teeth were found to be maximum in the molars and the least in anterior group. Overall, the maximum faciolingual width in the restored tooth was higher than the comparable control tooth.

The internal line angle for all types of tooth was in the range of 81.08 to 141.22 degrees compared with the ideal of 90 to 110 degrees recommended (34). The majority of preparations were therefore satisfactory, however, some preparations were well outside the ideal range yet crowns were able to be constructed for these preparations. It would be worth investigating whether there are any adverse clinical consequences (e.g. aesthetics, marginal durability, 
gingival inflammation) of crowns constructed where the internal line angles were not ideal.

It has been suggested that the ideal shoulder should be between 0.8 to $1.5 \mathrm{~mm}$ in width in order to allow for the optimum thickness of both metal and porcelain (30). This however, depends on the type of casting alloy used, because non-precious alloy requires less thickness compared with precious alloys. The majority of metal ceramic crowns placed in UK under the GDS appear to use semi-precious alloy (36). Therefore a minimum shoulder reduction of $1.0 \mathrm{~mm}$ is required. From our study the mean margin width for the three groups was between 0.89 to $0.97 \mathrm{~mm}$. From these data it would appear that there are deficiencies in the preparation regarding margin width with clinicians tending to underprepare the margin rather than overprepare. Other authors $(23,37)$ have found that compromising in shoulder width can have unfavourable consequences in contour and aesthetics. However, in this study, the linear regression analysis showed only a weak association between the width of margin and the emergence profile of restored tooth.

The small sample size used in this study was due to a number of factors:

1. Difficulty in identifying an intact and sound contralateral tooth on the stone model.

2. Most of the impressions of the contralateral teeth were poorly cast especially at the gingival margin area, therefore many models had to be excluded.

All measurements in this study were performed three times to get the most accurate value. The software used for measuring variables was in itself extremely accurate provided care was executed in its utilization. However, the long axis of the tooth had to be estimated and this was obviously a source of some error.

The measurements of emergence profile were only performed in one plane i.e. at the midline of the labial surface. From this one plane, it is impossible to fully assess the overall emergence profile of the tooth or crown, but it was felt that these areas would be reasonably representative of the whole crown.

\section{CONCLUSION}

In this in vitro study, the emergence profiles of crowns were higher than the contralateral teeth. Maxillary metalloceramic crown preparations had midline shoulder widths that did not conform to recommendations published in standard texts but line angles were within a satisfactory range. The margin width of the preparation exerts a weak effect upon the emergence profile of the crown.

\section{REFERENCES}

1. Black GV. Operative Dentistry, vol.2. Chicago, Medico-Dental Publishing Co. 1908.

2. Loe H. Reactions of marginal periodontal tissues to restorative procedures. Int Dent J 1968; 18: $759-78$.

3. Ramfjord SP. Periodontal aspects of restorative dentistry. J Oral Rehabil 1974; 1: 107-26.

4. Yap UJ, Ong G. Periodontal considerations in restorative dentistry. Part 2: Prosthodontic considerations. Dent Update 1995; 23: 13-6.

5. Becker CM, Kaldahl WB. Current theories of crown contour, margin placement, and pontic design. J Prosthet Dent 2005; 93: 107-15.

6. Flores-de-Jacoby L, Zafiropoulos G-G, Ciancio $\mathrm{S}$. The effect of crown margin location on plaque and periodontal health. Int J Periodont Rest Dent 1989; 3: 197-205.

7. Waerhaug J. The effect of rough surfaces upon gingival tissues. J Dent Res 1956; 35: 323-5.

8. Karlsen K. Gingival reactions to dental restoration. Acta Odontol Scand 1970; 28: 895904.

9. Newcomb GM. The relationship between the location of subgingival crown margins and gingival inflammation. J Periodontol 1974; 45: 151-4.

10. Valderhaug J, Ellingsen JK, Jokstad A. Oral hygiene, periodontal conditions and carious lesions in patients treated with dental bridges. A 15-years clinical and radiographical follow-up study. J Clin Periodontol 1993; 20: 482-9.

11. Lang NP, Kiel RA, Anderhalden K. Clinical and microbiologic effect of subgingival restorations with overhanging or perfect margins. J Clin Periodontol 1983; 10: 563-78.

12. Wheeler RC. Some fundamentals in tooth form. Dental Cosmos 1928; 70: 889-92.

13. Wheeler RC. Restoration of gingival or cervical margins in full crowns. Dental Cosmos 1931; 73: 238-42.

14. Wheeler R.C. Complete crown form and the periodontium. J Prosthet Dent 1961; 11: 722-34. 
15. Morris ML. Artificial crown contours and gingival health. J Prosthet Dent 1962; 12: 114656.

16. Yuodelis RA, Weaver JD, Sapkos S. Facial and lingual contours of artificial complete crown restorations and their effects on the periodontium. J Prosthet Dent 1973; 29: 61-6.

17. Sundh B, Kohler B. An in vivo study of the impact of different emergence profiles of procera titanium crowns on quantity and quality of plaque. Int J Prosthodont 2002; 15: 457-60.

18. Croll BM. Emergence profile in natural tooth contour. Part 1: Photographic observations. J Prosthet Dent 1989; 62: 4-10.

19. Koidis PT, Burch JG, Melfi RC. Clinical crown contours: contemporary view. J Am Dent Assoc 1987; 114: 792-5.

20. Kuo SB, Hong HH, Tsai TP, Shen YF. Developing an optimal emergence profile of the definitive restoration with a modified impression cap technique for ITI solid abutment. Prosthet Dent 2002; 88 : 646-8.

21. Croll BM. Emergence profile in natural tooth contour. Part 2: Clinical considerations. J Prosthet Dent 1990; 63: 374-9.

22. Ferencz JL. Maintaining and enhancing gingival architecture in fixed prosthodontics J Prosthet Dent 1991; 65: 650-7.

23. Stein RS, Kuwata M. A dentist and a dental technologist analyze current ceramo-metal procedures. Dent Clin North Am 1977; 21: 72949.

24. Jameson LM, Malone WFP. Crown contours and gingival response. J Prosthet Dent 1982; 47: 620-4.

25. Tung FF, Nourbakhsh N, Bahn C. Accurate procedure for simultaneous registration of gingival emergence profile and maximal intercuspal position for metal ceramic restorations. J Prosthet Dent 2000; 83: 681-5.

26. Goodacre CJ, Campagni WV, Aquilino SA. Tooth preparations for complete crowns: An art form based on scientific principles. J Prosthet Dent 2001; 85: 363-76.
27. Hooper SM, Huggett R, Foster LV. Teaching veneer and crown margins in UK dental schools. Dent Update 1993; 20: 192-6.

28. Sozio RB. The marginal aspect of the ceramometal restoration. The collarless ceramometal restoration. Dent Clin North Am 1977; 21: 787-801.

29. Shillingburg HT, Hobo S, Fisher OW. Preparation design and margin distortion in porcelain fused to metal restorations. J Prosthet Dent 1973; 29: 276-84.

30. Seymour KG, Samarawickrama DYD, Lynch EJ. Metal ceramic crowns - a review of tooth preparation. Eur J Prosthodont Rest Dent 1999; 7: 79-84.

31. Seymour K, Zou L, Samarawickrama DYD, Lynch E. Assessment of shoulder dimensions and angles of porcelain bonded to metal crown preparations. J Prosthet Dent 1996; 75: 406-11.

32. Hunter AJ, Hunter AR. Gingival crown margin configurations: A review and discussion. Part 1: Terminology and widths. J Prosthet Dent 1990; 64: 548-52.

33. Burke FJT. A synopsis of the adult dental health survey: Oral health in the United Kingdom 1998. Dent Update 2001; 27: 184-6

34. Seymour KG, Samarawickrama DYD, Zou L, Lynch E. Shoulder dimensions and angles of bonded crown preparations. J Dent Res 1995; 74 : 553. Abs 1219.

35. Alhouri N, Watts DC, McCord JF, Smith PW. Mathematical analysis of tooth and restoration contour using image analysis. Dent Mat 2004; 20: 893-9.

36. Northeast SE, Van Noort R, Johnson A, Winstanley RB, White GE. Metal-ceramic bridges from commercial laboratories: alloy composition, cost and quality of fit. Br Dent $\mathbf{J}$ 1992; 172: 198-204.

37. Donovan T, Prince J. An analysis of margin configurations for metal ceramic crowns. J Prosthet Dent 1985; 53: 153-7. 